\title{
Discussion on the Value and Development of Long-distance Exercise in Universities under the Craze of Marathon
}

\author{
Hefeng Zou ${ }^{1, a *}$, Wei Li ${ }^{2, b}$ and Manman Liü, \\ ${ }^{1}$ Chengdu Neusoft University, Sichuan \\ ${ }^{2}$ Chengdu Neusoft University, Sichuan \\ ${ }^{3}$ Chengdu Neusoft University, Sichuan \\ azoumenghappy@163.com, 'bliwei15827457696@163.com, 514216988@qq.com \\ * The corresponding author
}

Keywords: Marathon sports; Long - distance exercise; Value; Development

\begin{abstract}
With the development of national economy and the improvement of people's living standards, the marathon sports has been developing vigorously, and the number of events and participants rising constantly. However long-distance exercise in college is not hot, and the physical condition of students is also declining year by year. This paper analyzes the positive influence of long-distance running on students, and puts forward some countermeasures to develop campus long-distance running in the context of marathon fever.
\end{abstract}

\section{Introduction}

With the development of economy, people's awareness of sports is awakening gradually and pays more attention to their own physical health. The government also guides the residents to participate in physical exercise actively, especially with the state council issued the documents "Some Opinions on Accelerating the Development of Sports Industry to Promote Sports Consumption", the urban marathon sport has developed in a spurt. On the contrary, as the main force of youth sports education, long-distance exercise in college is not hot, and the physical condition of students is also declining year by year. It is worth discussing what causes this opposite situation.

\section{The Positive Influence of Long-distance Exercise}

Strengthen physique and improve physical quality of students. At present physical fitness of college students in our country decline year by year, and irregular diet and lack of exercise are the main reasons for this phenomenon. As an aerobic exercise, long-distance exercise can exercise ability of myocardial contraction of students, increase the ability of the heart to pump blood, strengthen the body's cardiovascular function, increase aeration capability of the alveolar bubbles and lung capacity, and have a positive impact on cardiopulmonary function. It can also improve body fat ratio and athletic ability. Therefore, carrying out long-distance exercise can enhance students' physical fitness effectively and improve their physical quality.

Shape personality and improve the psychological quality of college students. Persistence is the most precious in long-distance running. From a physiological point of view, there will be a pole in the process of running and the second breath. Pole appears when the runners have difficulty in breathing, quaking. They have the feeling of fatigue and feel very pain. This condition is a process by which the body regulates its potential to adapt to exercise intensity. Once the runners pass the pole persistently and the body adapt to the intensity of the exercise, it will feel relaxed again. The process of going from pole to second breath is similar to the process of people experiencing difficulties and overcoming them. Every step of running is a conversation with you. A marathon player who has participated marathons many times said that it is not so boring in more than forty kilometers running process, and there are all kinds of feeling for body and all kinds of reaction for mind. It is fun to keep fighting it. Life is like running which is all about you. Without a partner or an 
adversary, you must cultivate yourself and surpass yourself. So running brings you a better version of yourself.

Develop good sports attitude and lifestyle habits. The result of the national survey on physical health of students from 1985 to 2014 show that the physical health of college students in China shows a trend of continuous decline, and the decline in endurance quality is most obvious. Compared with 1985, the lung volume of college students decreased nearly 10 percent; 800 -meter of college boys runs decreased 10 percent; 1000-meter of college girls decreased 10.9 percent. The main reason for this phenomenon is that many college students have bad living habits such as sleep late, skip breakfast, and play games all night, lack of physical activity. In the long run, it will not only bring damage to the body, but also make a person weak in will and negative decadence. Many scholars have put forward corresponding countermeasures and suggestions on this phenomenon. The central committee of the communist youth league and the ministry of education jointly launched the SanZou activities on get off the Internet, walk out of the dormitory and walk toward the playground. Some results have been achieved, but it is not significant. However, long-distance exercise is an effective way to solve this problem. Long-distance exercise represents a kind of attitude and requirement. The positive energy extracted from running, such as persistence, ponders and perseverance will certainly inspire every aspect of runners' life. A student who has demands on himself and yearns for life will not let himself go. With persistence of long-distance running, it will enable participants to have a positive personality and good living habits.

\section{The Restrictive Factors of Long-distance Exercise in Universities}

Cognitive biases. For a long time, education pays more attention to education in literature than in sports in our country, exam-oriented education thought is still very common. Although the country is gradually promoting the position of sports in education in recent years and issued a series of positive policy. Many leaders in university don't know much about the function of sports, which affects the atmosphere of sports activities in campus directly. It needs to understand and implement the national education policy correctly, understand the relationship between physical education and moral education, intellectual education correctly, ensure students' time for extracurricular sports activities, develop and organize students to participate in physical exercise opportunities actively, and cultivate sports attitudes and awareness actively for creating a good college atmosphere of sports. As what Tsinghua University is doing now, it carries out campus sports activities from two aspects of policy enforcement and interest guidance. The idea of no sports and no Tsinghua permeates every student's mind.

There's a security risk. According to incomplete statistics, more than 40 people died after middle and long distance running in China from 2012 to 2014. The sudden deaths have caused widespread public concern and heated media debate, which pushed school sports to the forefront. The media has expanded the cases of sudden death, but ignored the causes, which makes long-distance exercise dangerous in the eyes of the public. Numerous leaders in domestic universities trend to cancelled long-distance exercise in sports meetings to avoid students' safety problem caused by accident in running. However this kind of behavior is bound to affect the development of long-distance running in colleges and universities.

\section{The enlightenment of Marathon to long-distance exercise in universities}

Compared with long-distance running in universities, marathon can blossom everywhere and is popular with the public. The reasons are as follows. First of all, there are various kinds of events. In addition to the full marathon and half marathon, there are shorter distance running, experience running and other events to attract people of different physical conditions to participate in. There will be a memorial medal for participants who completed the full marathon and half marathon successfully. This reward is the proof and encouragement to the participants, which will give them a great sense of achievement after the hard work and persistence. Second, Marathon focuses on race 
experience of participants. There will be many spectators cheer up to participants on both sides of the track in Marathon, many drinks and fruits provided by the volunteers enthusiastically and medical staff providing services to relieve muscle soreness after the game, which will give participants a good experience. Finally, pay attention to safety. Each participant must provide a physical examination certificate before enter the competition. The organizers of Marathon also buy accident insurance for each participant before the race. They also set up many medical treatment points in the process of Marathon to deal with emergencies.

\section{Suggestions and Countermeasures for Carrying out Long-distance Exercise in Universities}

At the ideological level, leaders of university should recognize the education function of sports and its role in promoting comprehensive development of individuals. The positive energy extracted from physical activity, such as persistence, thinking, perseverance, and discipline will certainly inspire participants in all aspects of their lives. It enables participants have a positive personality and good living habits insisting on sports games. The essence of education is to civilize its spirit, to strengthen its body, to internalize its heart and to shape its body. It is difficult to achieve this goal in exam-oriented education, and leaders of university should attach importance to the position of sports in education and keep it throughout education. The experience and harvest that long-distance running brings to participants cannot be replaced by other projects. Besides, it is easy to do in universities, so long - distance exercise should be promoted in university.

At the policy level, strengthen policy enforcement and guidance. Long-distance running and swimming are the items which can lead to cannot graduate from Tsinghua if not up to the standard, which is also the characteristic of Tsinghua. It is worth learning from Tsinghua University by forcing and guiding to lead students to exercise. Universities should formulate corresponding policies to promote students participate in sports activities according to the specific situation of the school, which should ensure the quality and participation of physical education and cannot cancel endurance aerobic exercise such as middle and long distance running for any excuse. We can consider the scores or times of students participating in middle and long distance races as a part of the comprehensive quality assessment of students. Do physical examination of the students on a regular basis. The results can be regarded as an important criterion for graduation assessment. At the same time, the school should create good conditions for students to participate in sports activities, enhance the running atmosphere of the school and attract more students to participate in, which can refer to the organizational form of Marathon to carry out various forms of middle-distance activities, such as fluorescent night running, long-distance running relay and other activities.

At the level of knowledge promotion, strengthen the publicity and popularization of scientific fitness knowledge. Only with scientific exercise can improve people's physical fitness. As aerobic endurance project, middle-distance exercise have bigger stimulus and mobilize for the respiratory system and cardiovascular system of body. Once there is a hidden disease in body or participate in exercise with no scientific way, it is very easy to have an accident. So there must be a scientific method to guide the middle-distance exercise to improve gradually. Schools can teach students considerations and exercise method about middle-long-distance exercise in physical education course. Students should choose an appropriate way to participate in exercise according to their own physical conditions and endurance indicators.

At the level of management, the school should take good management measures for long-distance exercise and take good safety precautions. Opinions of the state council of the central committee of the communist party of China on strengthening the physical fitness of young people through sports point out clearly that school should establish an emergency management mechanism for accidents, establish and improve the accident insurance system for young people. Universities should establish and improve the treatment measures for sports accident, promote and mobilization for college students to buy accident insurance to provide a guarantee for each students participating in sports. 


\section{Summary}

Long-distance education plays an important role in education of student, which can strengthen physique and improve physical quality of students, shape personality and improve the psychological quality of college students, develop good sports attitude and lifestyle habits. However longdistance exercise in college is not as hot as Marathon sports. This paper analyzes the reason of its existence and puts forward countermeasures at the level of ideological, policy, knowledge and management with reference of Marathon.

\section{References}

[1]B. Liu, J.M.Liu: China School Physical Education, Vol.3 (2016) No.1, p.51-55. (In Chinese)

[2]F.F.Li,L.Y. Yi:Journal of Exercise Science \& Fitness, Vol.15(2017)No.2,p.49-54.

[3]Xue-qin Tan:Journal of Nanjing Sport Institute,Vol31(2017)No.1,p.35-41.(In Chinese)

[4]Zhenquan Lin,Fan Meng: Physica A: Statistical Mechanics and its Applications, Vol.10(2017)No.8,p.87-97.

[5]G.E.Jowett,A.P. Hill,D. Forsdyke,A. Gledhill: Psychology of Sport \& Exercise, Vol.10(2018)No.4,p.26-32.

[6]Le Liu: Study on the Present Situation and Countermeasures of Campus Marathon Universities (MS.,Nanjing Normal University,China 2017),p.1-53.

[7]Yiran Yang: 2017 national competitive sports scientific paper report meeting (Tian Jin,China, October 13-15,2017).Vol.2,p.235-236.(In Chinese)

[8]Xiaolin Zhang: The 6th China sports doctor senior level BBS (Zhe Jiang,China, October 13-15,2016) Vol.2,p.104-105.(In Chinese)

[9]Xiangcai Lin,Ting Liu:2014 World Congress of Sociology of Sports and China's Annual Meeting of the Sociology of Sport(Bei Jin, China, July10-12,2014) Vol.2,p.65-66.( In Chinese)

[10]Yuke Jia: 2017 national competitive sports scientific paper report meeting (Tian Jin,China, October 13-15,2017).Vol.2,104-105. (In Chinese) 